\title{
Cuerpo, alegría y tristeza en la teoría del conocimiento de Sophie de Grouchy
}

\author{
Body, joy and sadness in the theory \\ of knowledge of Sophie de Grouchy
}

RICARDO HURTADO SIMÓ*

\begin{abstract}
Resumen: Sophie de Grouchy (1764-1822) realiza una teoría del conocimiento empirista basada en la importancia del placer y el dolor físico. Tiene la influencia de pensadores empiristas como Locke y Condillac así como de quien fue su marido, Nicolás de Condorcet. En su obra más destacada Cartas sobre la simpatía, desarrolla su gnoseología, donde conecta conocimiento, ética y filosofía política desde un trasfondo social y comprometido con los más desfavorecidos que rechaza la ética de Adam Smith porque es demasiado individualista y egoísta. De Grouchy defiende que el dolor físico y moral crea vínculos entre personas a través de la "simpatía", sobre todo hacia las personas más débiles; contra Smith, sostiene que nuestra simpatía es más intensa con el dolor que con el placer de los demás y, además, la conexión con las personas que sufren "humaniza" y refuerza los vínculos sociales.

Palabras clave: Placer, dolor, simpatía, cuerpo.
\end{abstract}

\begin{abstract}
Sophie de Grouchy (1764-1822) makes a knowledge theory based on empirism and on the importance of physical pain and physical pleasure. Having the influence of empiricist philosophers, such as Locke, Condillac and also who was her husband, Nicolas de Condorcet, de Grouchy's main book Letters on sympathy, explains her gnoseology. In that work, de Grouchy connects her knowledge theory with her ethical and political ideas from a social point of view really interested in weak people with needs. She also refuses Smith's ethical theory because it is so individualistic an selfish. De Grouchy argues that physical and moral pain create human links through "sympathy" and against Adam Smith philosophy, she thinks that sympathy is stronger with pain than pleasure. Furthermore, de Grouchy says that sympathy humanizes and reinforces human links.
\end{abstract}

Key words: Pleasure, pain, sympathy, body.

\section{Planteamiento del problema: la sensación compuesta}

Una primera lectura de las Cartas sobre la simpatía, obra de referencia de Sophie de Grouchy, nos deja ver con claridad que es una pensadora empirista. Al comienzo de su obra,

Fecha de recepción: 20/05/2016. Fecha de aceptación: 27/08/2016.

* Asistente honorario de la Facultad de Filosofía y miembro del grupo de trabajo "Filosofía de la cultura" de la Universidad de Sevilla. Centra sus investigaciones en los estudios de género, la historia de la filosofía y la Ilustración francesa. Recientemente ha publicado los libros La filosofía de Sophie de Grouchy: gnoseología, ética, política y feminismo, Centro de Estudios Políticos y Constitucionales, Madrid, 2014, y El ocaso del optimismo. De Leibniz a Hamacher. Debates tras el terremoto de Lisboa de 1755, Biblioteca Nueva, Madrid, 2016. rhurtadosimo@hotmail.com 
principalmente en las tres primeras cartas, de Grouchy trata genéricamente nociones manifiestas de la tradición sensualista, y en concreto de John Locke, autor conocido de primera mano por ella, e incluso citado en la carta número cuatro ${ }^{1}$ al hilo del estudio del origen de las ideas en los niños. Ya en la segunda página de la primera carta se introduce la noción de "sensación compuesta", al plantearse la necesidad de conocer las causas de la simpatía entre personas cuando cabe la posibilidad de enfrentarse a un daño corporal:

Todo dolor físico produce una sensación compuesta en la persona que lo sufre. Primeramente, produce un dolor local en la parte en la que dicha causa del dolor actúa inicialmente. Asimismo, produce una impresión dolorosa en todos nuestros órganos, una impresión muy distinta del dolor local y que siempre acompaña a dicho dolor, pero que puede continuar existiendo sin él. ${ }^{2}$

El inicio del estudio de la simpatía nos sitúa ante las sensaciones, que son el punto de partida de toda facultad o idea y de nuestro contacto físico e intelectual con el mundo exterior. La idea esencial es estudiar la simpatía partiendo de sus raíces fundamentales, desde una óptica empirista que no surge del ejercicio de las facultades intelectuales sino de las facultades sensibles de los seres vivos, del cuerpo entendido como un todo capaz de recibir informaciones del mundo exterior. Al respecto, de Grouchy tiene como base los planteamientos de Locke en torno a las nociones de sensación y experiencia ${ }^{3}$, pero avanza sobre ellos hasta desarrollar el concepto de sensación compuesta, resultado del efecto que una afección local provoca en el estado general del cuerpo, ya sea aplicado tanto al dolor como al placer. Asimismo, combina el empirismo lockeano con la metodología de Condillac, consistente en buscar exhaustivamente las primeras causas del conocimiento y el origen de las ideas de sensación o dolor. ${ }^{4}$ Sin embargo, de Grouchy se aleja del reduccionismo sensista de Condillac y hace especial hincapié en el proceso reflexivo del sujeto que está en contacto con el mundo a través de los sentidos pero también, del pensamiento.

\section{La importancia de la imaginación en el recuerdo del dolor}

Si Hume señalaba que las impresiones podían dividirse en impresiones de sensación e impresiones de reflexión y que estas últimas podían reaparecer por medio de la memoria o la imaginación ${ }^{5}$, de Grouchy se apropia de estos planteamientos pero los modifica sensiblemente, sosteniendo que la impresión general es fruto de la imaginación. El pensador nacido en Edimburgo descomponía la posibilidad de que las impresiones reaparecieran en dos tipos, de manera intermedia, con una fuerza entre la de una impresión y una idea, gracias a la memoria, y como meras ideas, como copias débiles o imágenes y las impresiones, gracias a la imaginación. Ahora bien, de Grouchy distingue entre impresión general que:

1 De Grouchy, S., Cartas sobre la simpatía, Sevilla, Padilla libros y editores, 2011, p. 122.

2 Ibid., p. 82.

3 Véase, Locke, J., Ensayo sobre el entendimiento humano, Madrid, Editorial Nacional, 1980, p. 164.

4 Condillac, Traité des sensations, en Martínez Líebana, I., Tacto y constitución del mundo. La teoría del Conocimiento de Condillac, Madrid, Editorial de la Universidad Complutense de Madrid, 1990, p. 85.

5 Hume, D., Tratado de la naturaleza humana, Barcelona, RBA, 2002, p. 81. 
(...) depende de la sensibilidad y sobre todo de la imaginación. Esta impresión es más intensa cuanto más fuerte es nuestra sensibilidad, y su reproducción es conmensuradamente más sencilla en cuanto la impresión sea más intensa y nuestra imaginación sea más capaz de recibir y conservar todas las ideas que pueden reproducirla. ${ }^{6}$

Y por otra parte la idea de la impresión general:

(...) producida por contemplar un daño físico (que) se renueva más fácilmente cuando presenciamos aflicciones que nosotros mismos ya hemos sufrido, porque esas impresiones se despiertan tanto por nuestros recuerdos como por la contemplación de su objeto. $^{7}$

Mientras que la memoria tiene la capacidad de rememorar las sensaciones e impresiones pasadas siguiendo un cierto orden y posición, la imaginación destaca por su mayor potencialidad, por su capacidad de añadir a la memoria la facultad de combinar y reagrupar ideas, de componer y descomponer impresiones pasadas de manera arbitraria y no ordenada. La imaginación se distingue de la memoria porque añade libertad plena. Hay una clara base asociativa que nos permite hablar de impresiones generales e ideas de impresiones generales, pero la imaginación trasciende los límites del simple recuerdo. Al respecto, de Grouchy recurre a una experiencia personal:

Conocí una mujer que leyó un pasaje muy detallado sobre las enfermedades del pulmón en un trabajo médico, y cuya imaginación se estremeció por las numerosas causas capaces de afligir a este órgano vital; tanto es así que creyó experimentar ciertos dolores que caracterizan la pulmonía, y tuvo problemas para deshacerse de esa idea. Ejemplos similares no son extraños, especialmente en esa clase de individuos cuyas compasivas y ociosas vidas les dejan numerosos caminos para protegerse a sí mismos de ser conducidos a conclusiones erróneas a causa de una imaginación muy activa. ${ }^{8}$

La importancia de la imaginación en el proceso cognoscitivo también puede verse en el citado Condillac; la imaginación nace como fruto de la relación entre las percepciones recibidas; al respecto, distingue dos tipos de imaginación: la imaginación reproductora, que consiste en actualizar o recordar una percepción pasada; y la imaginación creadora, que es lo que comúnmente entendemos por imaginación. Este segundo tipo de imaginación está mucho más en la línea de las posiciones de Grouchy, ya que es capaz de combinar en un solo objeto diferentes cualidades y rasgos encontrados en varios. En La Logique, Condillac la considera una modificación de la reflexión, mientras que en el Traité des sensations está más ligada a la memoria:

\footnotetext{
6 De Grouchy, op. cit., pp. 84-85.

7 Ibid., p. 85.

8 Ibidem.
} 
Cuando por la reflexión se han observado las cualidades por las que difieren los objetos, podemos mediante la misma reflexión, reunir en uno solo las cualidades que están diseminadas en varios. Así es como un poeta se forma, por ejemplo, la idea de un héroe que jamás ha existido. Entonces, las ideas que se hacen son imágenes que solo tienen realidad en el espíritu; y la reflexión que crea estas imágenes recibe el nombre de imaginación. ${ }^{9}$

Tanto para Condillac como para de Grouchy, la imaginación es ante todo una fuerza reproductora que tiene su base en la memoria pero que es capaz de traspasar sus fríos límites para sentir vivamente aquello que se imagina. Respecto a Hume, de Grouchy se distancia del filósofo de Edimburgo al afirmar que la impresión general está causada por la imaginación, algo a lo que no llega Hume, quien se limita a hablar de impresión.

\section{La simpatía ante el placer y el dolor. La polémica Smith-de Grouchy}

Como indicamos al comienzo de nuestra ponencia, uno de los puntos en los que de Grouchy quiere distanciarse de Smith es en lo que respecta a qué es más fuerte en nuestra simpatía hacia los demás, si el placer o el dolor. La propuesta de Grouchy llama la atención por la intensidad con la que afirma que nuestra capacidad de simpatizar es mucho más fuerte hacia el dolor tanto físico como moral, que hacia el placer; la filósofa nacida en Meulan defiende que nos afecta más el daño que el gozo y, en concreto, el daño corporal que el moral o intelectual:

La simpatía por los sufrimientos morales es más fuerte que ante los placeres morales, y por la misma razón, es más fuerte ante los daños físicos que ante los placeres físicos. ${ }^{10}$

Algunos especialistas sobre la figura de Sophie de Grouchy han considerado que su teoría sobre los sentimientos y las sensaciones podría ser considerada una respuesta contra la doctrina metafísica del espectador imparcial. Para ella, estamos afectados por un sentimiento abstracto y por la mala sensación que tenemos de hacer el mal, de producir dolor a las otras personas. Por el contrario, para Smith, nos sentimos mal, pero al principio, como resultado de un externo y objetivo punto de vista. Según de Grouchy, los sentimientos abstractos se desarrollan más allá de nuestra experiencia y por encima de la suma de buenas acciones. Y la moral está profundamente enraizada en nuestra naturaleza:

Hasta este punto, mi querido Cabanis, he mostrado cómo la sola simpatía física se convierte en simpatía individual, fortificada por diversas circunstancias, más activa y energética por el entusiasmo, naciendo en nosotros las penas y los placeres morales. ${ }^{11}$

9 Martínez Liébana, op. cit., p. 105.

10 De Grouchy, op. cit., p. 126.

11 Para profundizar en esta tesis véase De Grouchy, S., Letters on sympathy. A critical edition, California, American Philosophical Society, 2008, pp. 19-34. 
En este trabajo sostenemos que no existe tal respuesta al espectador imparcial smithiano; de Grouchy no cita en ningún momento este concepto y, simplemente, se mantiene en otro plano, pues sus sentimientos e ideas abstractas son resultado del proceso de transformar sentimientos, impresiones e ideas concretas en generales y universales. Dichas abstracciones son solo nociones claras y sintetizadoras que los seres humanos crean en la conciencia. Nada tienen que ver con ese "representante y juez de nuestra conducta", "hombre dentro del pecho" que resulta ser el espectador imparcial; podemos decir que en de Grouchy, lo más parecido al espectador imparcial es la conciencia, que valora las acciones y decisiones humanas desde la objetividad y el recuerdo de situaciones pasadas. Asimismo, a Smith la teoría del espectador imparcial le conduce a una visión religiosa de la moral y de la conciencia humana ${ }^{12}$, tanto es así que lleva a denominarlo "semidios", algo que de Grouchy rechaza tajantemente. La moral de de Grouchy es totalmente laica, empirista y antimetafísica. Es más, en la carta sexta rechaza lo que denomina "sentido íntimo" al que Smith recurre para establecer las reglas generales de la moral, y que bien podría ser una crítica vedada al espectador imparcial:

Necesitamos rechazar, mi querido Cabanis, esta predilección de suponer un sentido íntimo, una facultad o principio siempre en acción, pues nos encontramos con un hecho que no podemos explicar. ${ }^{13}$

Volviendo al tema de la fuerza del dolor y el cuerpo, de Grouchy afirma que es mucho mayor que la del placer, y este es un fenómeno que puede incluso constatarse en primera persona: la duración de los dolores que sufrimos es mayor que la de los placeres; en definitiva, el placer es más volátil que el dolor. Y al hablar del plano intersubjetivo, ocurre lo mismo, pues la contemplación de una persona que sufre, o que intuimos que sufre, nos recuerda lo terrible de su sufrimiento y la huella que dejará, refrescando en nosotros esa desagradable y duradera sensación:

La simpatía, que la contemplación de placeres físicos nos hace volver a sentir, es de este modo un sentimiento con menos poder sobre nuestra alma que lo que nos inspira bajo la contemplación del dolor. Pero era importante constatar su existencia porque sirve para más fenómenos de la simpatía moral. ${ }^{14}$

Por tanto, en de Grouchy hay una clara primacía del dolor sobre el placer; realmente, su análisis del cuerpo podríamos calificarlo como una "anatomía del dolor", pues realiza un estudio exhaustivo sobre el dolor, su definición, causas y manifestaciones. Además, la simpatía entre personas es mucho más fuerte ante los padecimientos físicos que ante el placer o el dolor moral. Para fundamentar esta tesis, la autora recurre a la propia experiencia, señalando que el sufrimiento físico deja en nuestra memoria un legado mucho mayor que el sufrimiento moral. Las heridas del cuerpo tardan más en cicatrizar que las del espíritu.

12 Véase Elosegui Itxaso, M., «En torno al concepto de simpatía y el espectador imparcial en Adam Smith o la sociedad como espejo», Eurídice (Navarra), I, 1991, pp. 119-148.

13 De Grouchy, op. cit., p. 155.

14 Ibid., p. 89. 
Pero de Grouchy da un paso más y considera que esta simpatía hacia los sufrimiento de los demás varía en grado dependiendo de ciertas preferencias afectivas. Nuestro trato con las personas que nos rodean varía dependiendo de los vínculos que se establezcan; así, es más fuerte cuando afecta a personas que tenemos en alta estima o a las cuales debemos gratitud por la atención que nos proporcionaron a través de las diferentes etapas de la vida:

Veamos, en primer lugar, cómo estamos inclinados a simpatizar con las aflicciones de ciertos individuos más que con las de otros que experimentan similares o parecidas. Independientemente de las convenciones morales que constituyen gran parte de la felicidad y la existencia de las cuales el alma ha desarrollado y ejercitado, independientemente de todo lo que hace al hombre civilizado feliz, cada individuo se encuentra dependiente de muchos otros para satisfacer sus necesidades vitales, su bienestar y su comodidad. Esta dependencia, más extendida y marcada en la infancia, continúa en cierto grado en los años posteriores y permanece más o menos fuerte dependiendo de que el desarrollo moral la aparte a un lado o deje que permanezca. Pero, como la extrema desigualdad de fortunas reduce a la mayoría de los hombres en el estado de sociedad a ocuparse de sus propias necesidades físicas, la vasta mayoría de la especie humana está condenada a una estricta dependencia de todo aquel que puede ayudarle en satisfacer sus necesidades. A esto le sigue que cada individuo pronto reconoce a aquellos a los que les debe la mejor parte de su existencia y a quienes son las más próximas y permanentes causas de sus penas y alegrías. No puede ser indiferente a su presencia o a la idea de esta. Esa gente, sin duda alguna, le hace sentir dolor o placer. Esta dependencia específica con algunos individuos comienza en la cuna. ${ }^{15}$

La necesidad humana de convivir con otros semejantes, que desde el nacimiento nos proporcionan los medios necesarios para la supervivencia, genera unos vínculos afectivos naturales y espontáneos que acompañan toda la vida. En este punto, la simpatía brota como mecanismo natural y previo a toda determinación social. Uno de los motivos por los que Sophie de Grouchy se lanza a redactar sus Cartas sobre la simpatía es su disconformidad con Adam Smith en lo que respecta a este asunto, referente a la primacía del dolor del cuerpo sobre el moral y al rechazo smithiano a admitir que se produce una fuerte simpatía con los dolores:

Nuestra simpatía hacia los dolores físicos es más fuerte, más general y más dolorosa que hacia los sufrimientos morales; la exposición ante sufrimientos físicos es también desgarradora e inoportuna para aquellos que su educación, o más bien los errores de su educación, les han alejado de la imagen del dolor. ${ }^{16}$

Esta tesis choca radicalmente con la de Smith, que sostiene que es casi imposible establecer una conexión simpática con una persona que sufre de un dolor físico. De nuevo, de

15 Ibid., p. 94.

16 Ibid., p. 116. 
Grouchy critica el rechazo infantil con el que Smith se aleja de los dolores físicos, y al igual que cuando hablaba del amor, lo considera algo absurdo y poco fundamentado:

Smith establece la proposición contraria, y cree que la justifica diciendo que la imitación de dolores corpóreos difícilmente nos conmueve; este tipo de imitación es un hecho ridículo y contrario a la compasión, mientras que la imitación de sufrimientos morales despierta impresiones más intensas en el alma. Esto es debido a que la simpatía es más débil con un hombre cuya pierna ha sido cortada que con otro hombre que ha perdido a su amante. ${ }^{17}$

De Grouchy cita aquí literalmente una frase de Smith donde utiliza este ejemplo para rechazar nuestra simpatía por los dolores físicos:

La pérdida de una pierna puede generalmente ser considerada una calamidad más real que la pérdida de una amante. Pero cualquier tragedia cuyo desenlace catastrófico gira en torno a una pérdida como la primera sería algo ridículo. ${ }^{18}$

Para nuestra protagonista, independientemente de que ambos tengan planteamientos filosóficos diferentes, Smith yerra al mezclar dos planos completamente diferentes, el de la realidad y el del arte. Es innegable que el arte versa sobre la vida humana, sobre lo cotidiano, lo que tiene implicaciones morales, pero Smith realiza un salto demasiado grande. En el terreno artístico, la tragedia excita unas ciertas emociones en los espectadores a través de situaciones donde el dolor viene dado por las circunstancias y por los lazos afectivos, no por escenas desagradables para la vista:

Uno puede dudar al respecto; es solo porque la imitación de los dolores físicos necesarios para éxitos teatrales hace la ilusión más difícil de alcanzar; y esta imitación necesita también ser acompañada por dolores morales para producir un justificado y variado interés. Y es, finalmente, porque el interés de la tragedia reside claramente en el talento de hacer compasiva la simpatía hacia las desgracias de otros por medio de una progresiva excitación de nuestra sensibilidad, y no ofreciéndonos de repente una descorazonadora imagen de un sufrimiento físico, una imagen de la que no podemos dejar de pensar si nos invade, y que se transforma en ridícula si no se piensa en ella. ${ }^{19}$

Sin embargo, la raíz de las diferencias entre Smith y de Grouchy no radica en una confusión entre planos. La causa por la que Smith sostiene que nuestra simpatía por el dolor físico es casi nula se basa en que, a diferencia de de Grouchy, establece la imaginación como motor del mecanismo simpático. Como vimos con anterioridad, según Smith, hay una primacía de la imaginación sobre el cuerpo; el plano intelectivo prima sobre el sensitivo, "Lo primero que nos perturba no es un objeto de los sentidos, sino una idea de la imaginación."20

17 Ibid., pp. 116-117.

18 Smith., op. cit., p. 86.

19 De Grouchy, Cartas sobre la simpatía., p. 117.

20 Smith., op. cit., p. 86. 
A diferencia del dolor físico, el dolor moral permite desplegar en nuestra mente (merced a la imaginación) toda una catarata de ideas y fantasías que nos preocupa y entristece, provocando que simpaticemos con la persona sufriente:

Nada se olvida tan pronto como el dolor. En el momento en que se va se acaba toda la agonía, y el pensar en él no nos causa perturbación alguna. Nosotros mismos no podemos adoptar la ansiedad y la angustia que sentíamos antes. Un comentario descuidado de un amigo dará lugar a una inquietud mucho más duradera. ${ }^{21}$

Ahora bien, pese a que es innegable que existen diferencias entre las tesis de Smith y las de de Grouchy, una lectura atenta de La teoría de los sentimientos morales saca a la luz que la posición de Smith respecto a los dolores físicos no es exactamente la que señala nuestra protagonista. Aquel defiende la primacía de la simpatía por los dolores morales sobre los físicos, pero sin rechazar totalmente estos últimos. Conforme avanza en su escrito, señala que nuestra simpatía con las penas de los otros es más intensa que con las alegrías y placeres, aunque nunca al nivel que siente la persona que lo experimenta:

Asimismo, el dolor, de la mente o del cuerpo, es una sensación más punzante que el placer, y nuestra simpatía con el dolor, aunque no llegue ni de lejos a lo que naturalmente sufre el paciente, es generalmente una percepción más clara e intensa que nuestra simpatía con el placer (...). ${ }^{22}$

Un poco más adelante, Smith refuerza su posición sosteniendo que egoístamente, pese a que seamos más capaces de simpatizar con adversidades que con alegrías, esta sensibilidad no nos resulta rentable. Simpatizar más con el daño que con la felicidad acarrearía en nosotros un sentimiento de malestar que resultaría pernicioso:

(...) aunque nuestra simpatía con el pesar es a menudo una sensación más punzante que nuestra simpatía con el gozo, siempre se queda muy lejos de la violencia de lo que es naturalmente sentido por la persona principalmente afectada. Simpatizar con la alegría es grato (...). Pero es penoso adoptar la aflicción y somos reacios a hacerlo. ${ }^{23}$

Desde este punto de vista, lo que diferencia a ambos autores gira en torno a dos puntos: la intensidad y la utilidad. En de Grouchy, la intensidad que sentimos al simpatizar con los dolores físicos de quien sufre es notable; en Smith, es tibia, y mucho mayor con los dolores morales merced a la intervención de la imaginación, que asocia el dolor con las diversas consecuencias y circunstancias que pueden acompañarle. Respecto a la utilidad, Smith sostiene que naturalmente estamos inclinados a alejarnos del dolor, pues podría afectarnos negativamente; de Grouchy llega incluso a afirmara lo positivo del dolor y, en

21 Ibidem.

22 Ibid., p. 114.

23 Ibid., p. 116.

Daimon. Revista Internacional de Filosofía, Suplemento 5 (2016) 
concreto, del dolor físico que padece nuestro cuerpo, que nos introduce en el mundo real, humaniza y permite establecer vínculos con quienes sufren:

Podemos fácilmente formarnos la idea de que la impresión general producida por contemplar un daño físico se renueva más fácilmente cuando presenciamos aflicciones que nosotros mismos ya hemos sufrido, porque esas impresiones se despiertan tanto por nuestros recuerdos como por la contemplación de su objeto. Es por esta razón por lo que la escuela del dolor y la adversidad es muy eficaz para formar hombres más compasivos y mucho más humanos. ${ }^{24}$

\section{Bibliografía}

Condillac (1754): Traité des sensations, en Martínez Liébana, Ismael (1990): Tacto y constitución del mundo. La teoría del conocimiento de Condillac, Editorial de la Universidad Complutense de Madrid, Madrid.

De Grouchy, Sophie (2011): Cartas sobre la simpatía, Padilla libros y editores, Sevilla.

De Grouchy, Sophie (2008): Letters on sympathy. A critical edition, American Philosophical Society, California, 2008.

Elosegui Itxaso, María (1991): En torno al concepto de simpatía y el espectador imparcial en Adam Smith o la sociedad como espejo in Eurídice, UNED, Pamplona, pp. 119-148.

Hume, David (2002): Tratado de la naturaleza humana, RBA, Barcelona.

Locke, John (1980): Ensayo sobre el entendimiento humano, Editorial Nacional, Madrid.

24 De Grouchy, Cartas sobre la simpatía, p. 85. 
